\title{
Characterization of the role of dendritic cells in prion transfer to primary neurons
}

\author{
Langevin Christelle ${ }^{1}$, Gousset Karine ${ }^{1}$, Costanzo Maddalena ${ }^{1}$, Odile Richard Le Goff ${ }^{1}$, Zurzolo
} Chiara $^{1,2, *}$.

1 Institut Pasteur, Unité de Trafic Membranaire et Pathogénèse, 25 rue du Dr. Roux, 75724 Paris

Cedex 15, France

2 Dipartimento di Biologia e Patologia Cellulare e Molecolare, Università degli Studi die Napoli "Federico II", via Pansini 5, 80131 Naples, Italy

* Author to whom correspondence should be addressed:

Dr. Chiara Zurzolo, e-mail: zurzolo@pasteur.fr

Short title: Role of dendritic cells in prion transfer to neurons

Keywords: Dendritic Cells (DCs), cerebellar granule neurons (CGNs), tunnelling nanotubes (TNTs), intercellular transfer, prion infection

Abbreviation: Bone-Marrow derived Dendritic Cells (BMDCs), cellular prion protein (PrPc), Pathologic form of prion protein (PrPSc)

Transmissible spongiform encephalopathies (TSEs) are neurodegenerative diseases caused by pathogenic isoforms (PrPSc) of the host-encoded cellular prion protein (PrPc). After consumption of contaminated food, PrPSc deposits rapidly accumulate in lymphoid tissues before invasion of the central nervous system (CNS). However the mechanisms of prion spreading from the periphery to the nervous system are still unclear. In this study, we investigated the role of dendritic cells (DCs) in the spreading of prion infection to neuronal cells. First, we determined that bone-marrow derived dendritic cells (BMDCs) rapidly uptake PrPSc after exposure to infected brain homogenate. Next, we observed a progressive catabolism of the internalized prion aggregates. Similar experiments performed with BMDCs isolated from knock-out (KO) or mice over-expressing PrP (tga20) indicate that both PrPSc uptake and catabolism are independent of PrPc expression in these cells. Finally, using co-cultures of prion-loaded BMDCs and cerebellar neurons, we characterized the transfer of the prion protein and the resulting infection of the neuronal cultures. Interestingly, the transfer of PrPSc was triggered by direct cell-to-cell contact. As a consequence, BMDCs kept the prion protein when cultured alone and no transfer to the recipient neurons was observed when a filter separated the two cultures or when neurons were exposed to the BMDCs conditioned media. Additionally, fixed BMDCs also failed to transfer prion infectivity to neurons suggesting an active transport of prion aggregates, in accordance with a role of tunnelling nanotubes (TNTs) observed in the co-cultures.

\section{INTRODUCTION}

Transmissible Spongiform Encephalopathies (TSE) as variant of Creutzfeldt-Jacob Disease, scrapie or Chronic Wasting Disease can be acquired from the consumption of contaminated food. Following oral exposure, prions enter the host organism through the gut before invasion of the draining lymphoid tissues, where the first prion amplification takes place [1-3]. Prions subsequently spread to the CNS, where a characteristic neurodegeneration process is engaged concomitantly to the prion aggregates deposition in the brain [4-6]. Prior to prion neuroinvasion, PrP deposits are mainly visualized in tangible body macrophages and Follicular Dendritic Cells (FDCs) of the secondary lymphoid tissues (Peyer's Patches, mesenteric lymph nodes, spleen) [7-12]. 
While a number of studies suggest that FDCs could play an important role in prion replication, the mechanisms of prion spreading from the gastrointestinal tract to the FDCs and from lymphoid tissues to the CNS are still undetermined [13-15]. Prion neuroinvasion is initiated in the enteric nervous system and followed by retrograde transport along the sympathetic and parasympathetic nerve fibers [16-18]. Because of the absence of neuro-immune synapses between resident FDCs and nerve fibres, direct prion transfer mechanisms between these two cell types can be excluded [19-22]. Based on in vitro studies of intercellular prion transfer mechanisms, different hypotheses have been advanced. FDCs might passively transfer prion to proximal cells or nerve endings through exosomes or vesicle secretion [21, 23]. Alternatively, mobile haematopoietic dendritic cells (DCs) cells might transfer PrPSc from the gut to FDCs or possibly directly to nerves fibres. Indeed, different studies have characterized the role of DCs in the prion infection process [24-27]. DCs are mobile cells, which can directly uptake antigens by insertion of dendrites through the tight junctions of the intestinal epithelium cells [28] or after prion transepithelial migration through microfold cells [29, 30]. Following antigen capture, DCs can retain proteins in native form for a sufficient time to facilitate their subsequent migration to the targeted lymphoid tissues [31]. Furthermore, after TSE infection by the oral route, PrPSc deposits have been identified in DCs from Peyer's Patches, mesenteric lymph nodes or spleens [32, 33]. Finally peripheral prion infection performed in mice devoid of DCs failed to accumulate PrPSc in lymphoid tissues and the subsequent neuro-invasion was partially impaired [24, 27, 34]. Overall, these data strongly point to DCs as potentially important candidates in prion transport from the gut to the lymphoid tissues, even though the subsequent neuroinvasion mechanisms are still undetermined. In addition, contrary to FDCs, DCs can theoretically promote prion transfer to nerve cells by direct contacts with nerve fibres $[32,33,35,36]$ or through tunnelling nanotubes (TNT)-like structures [37, 38]. Indeed BMDCs are able to form TNT-like structures in vitro when co-cultured with primary neurons and can transfer PrPSc and infection to these cultures [37, 38].

In this study, we have characterized the role of BMDCs in the transfer of prions to primary neurons using an in vitro approach. First, we analyzed the uptake and the fate of scrapie homogenate in BMDC cultures. We demonstrated that BMDCs rapidly internalize PrPSc aggregates and keep them for several hours, independently of the PrPc expression levels. Next, we characterized the transfer of PrPSc from prion-loaded BMDCs to primary neurons using short time co-cultures. We found that BMDCs begin to transfer PrPSc as early as 4 hours after cell cultures has been established and that this transfer is triggered by cell-to-cell contact. Furthermore, we show that PrPSe transfer results in prion infection (eg; prion replication) of primary neurons. Overall, our study demonstrates that DCs can discharge prions to target cells upon direct cell-to-cell contact and confirms that TNTs could be a major transfer mechanism in the passage of prions from the periphery to the CNS.

\section{EXPERIMENTAL}

\section{Mouse lines}

Primary cultures were established from C57BL/6J mice provided by Charles River Laboratories or the transgenic mouse lines PrP0/0 (PrP knockout mice) (Zurick I) [54] and tga20 (mouse Prnpa allele) [55] provided by the CDTA. All experiments were performed according to national guidelines.

\section{Cell culture}

Primary cultures of cerebellar granule neurons (CGNs) were established as previously described [50]. Briefly, CGNs were extracted from brains of 6 days old C57BL/6 mice by enzymatic and mechanical dissociations. They were plated at a density of 800,000 cells/well in 12-well plates coated with $10 \mu \mathrm{g} / \mathrm{mL}$ of poly-D-lysine (Sigma) and cultivated in Dulbecco's modified Eagle's medium (Gibco) containing 10\% fetal calf serum, $20 \mathrm{mM} \mathrm{KCl}$, penicillin $(50 \mathrm{U} / \mathrm{mL})$, streptomycin 
$(50 \mu \mathrm{g} / \mathrm{mL})($ Gibco) and complemented with B27 and N2 supplement (Gibco). Cultures were incubated at $37^{\circ} \mathrm{C}$ in humidified atmosphere with $5 \% \mathrm{CO} 2$ and were complemented weekly with $1 \mathrm{mg} / \mathrm{mL}$ Glucose and $10 \mu \mathrm{M}$ of the anti-mitotics uridine and fluorodeoxyuridine (Sigma) to avoid proliferation of astrocytes. As negative controls, CGN cultures were established from $\mathrm{PrP} 0 / 0$ mice.

Bone-marrow derived dendritic cells (BMDCs):

BMDCs were differentiated from bone marrow cells from 6- to 8-week-old C57BL/6 mice according to a method adapted from Méderlé et al [56]. Briefly, bone marrow cells were seeded at $5 \times 10^{6}$ cells per $100 \mathrm{~mm}$ diameter Petri dish (Falcon, Becton Dickinson Labware, Franklin Lakes, $\mathrm{NJ}$ ) in 10ml of Iscove's modified Dulbecco's medium (RPMI 1640, GIBCO) supplemented with $10 \%$ heat-inactivated fetal calf serum, $20 \mathrm{ng} / \mathrm{mL}$ GM-CSF (R\&D system), penicillin $(50 \mathrm{U} / \mathrm{mL})$, streptomycin $(50 \mu \mathrm{g} / \mathrm{mL}), 50 \mu \mathrm{M}$ 2-mercaptoethanol. Cultures were incubated at $37^{\circ} \mathrm{C}$ in a humidified atmosphere with $5 \% \mathrm{CO}_{2}$. On day $3,10 \mathrm{ml}$ of complete RPMI was added. On day 6 , cells in suspension and loosely adherent cells were harvested. The recovered cells were further cultured under the same conditions as above. On day 10, cells were harvested with EDTA as above and distributed in CellBIND 6-well plates (Corning) at a concentration of $1 \times 10^{6}$ cells/well in $3 \mathrm{~mL}$ complete RPMI.

moRK13 were kindly provided by Dr Andrew Hill (Bio21 Institute, University of Melbourn). Cells were maintained at $37^{\circ} \mathrm{C}$ in $5 \% \mathrm{CO}_{2}$ in Opti-MEM media (GIBCO) supplemented with $10 \%$ fetal bovine serum, penicillin $(50 \mathrm{U} / \mathrm{mL})$, streptomycin $(50 \mu \mathrm{g} / \mathrm{mL})$.

\section{Prion loading of BMDCs}

Brain homogenates were prepared from the brains of mice terminally affected with the mouse 139A strain, from an original 139A affected brain kindly provided by Dr M. Baier (Robert Koch Institute, Berlin). Homogenates were diluted to a final concentration of $20 \%$ (wt/vol) in a $5 \%$ (wt/vol) glucose solution, sonicated in RPMI media and a suspension equivalent to $2.5 \mathrm{mg}$ of infected brain tissue was added to the wells of BMDC cells for the indicated times.

\section{Co-cultures}

BMDC-CGN co-cultures.

BMDCs were loaded with equivalent of $2.5 \mathrm{mg}$ of infected brain tissue for 18 hours. Two days after plating, CGNs were co-cultured with prion-loaded BMDCs overnight (ratio 4CGN/1BMDC). BMDCs were removed from the CGN cultures by extensive washes before analyses of PrPres in CGNs after short times (30 minutes to 4 hours) or after 2 and 3 weeks post co-culture. $50 \mu \mathrm{g}$ of protein was treated with $0.5 \mu \mathrm{g}$ of $\mathrm{PK}$ for $30 \mathrm{~min}$ at $37^{\circ} \mathrm{C}$ before methanol precipitation. Samples were then subjected to SDS analysis and Western Blot with anti PrP Sha31Ab. Same amounts were methanol precipitated without PK treatments and analyzed by SDS page and Western blot using M5/114 antibody (directed against MHC class II proteins specifically expressed in BMDCs cells) or GADPH antibody.

moRK13 were co-cultured with prion-loaded BMDCs for 18 hours at a 4/1 ratio. After overnight co-cultures, BMDCs were removed from the moRK13 by extensive washes. $20 \mu \mathrm{g}$ of proteins from BMDC or moRK13 cell extracts were treated with $0.5 \mu \mathrm{g}$ of PK for $30 \mathrm{~min}$ at $37^{\circ} \mathrm{C}$ before methanol precipitation. Samples were then subjected to SDS analysis and Western Blot with anti PrP Sha31Ab.

Co-incubations with fixed BMDCs were performed as indicated above after BMDCs fixation with a solution of $2 \%$ paraformaldehyde, $0.05 \%$ gluteraldehyde and $0.2 \mathrm{M}$ Hepes in PBS for $20 \mathrm{~min}$, followed by a second 20 min fixation with $4 \%$ paraformaldehyde and $0.2 \mathrm{M}$ Hepes in PBS. The cells were then washed thoroughly and added to the neuronal cells.

For the filter experiments, BMDCs were plated on $0.4 \mu \mathrm{m}$ filters (Colstar) on top of CGN cultures at 2 days post plating. After overnight co-cultures, the filters were removed and the neuronal 
cultures were analyzed at different time points post incubation. For the supernatant experiments, BMDCs were loaded with equivalent of $2.5 \mathrm{mg}$ of infected brain tissue as previously mentioned overnight. Loaded BMDCs were centrifuged at 12,000 rpm in RPMI and the supernatant was added to CGN cultures 2 days post plating. After overnight incubations with the supernatant, CGNs were lysed and analysed as previously mentioned.

\section{Imaging of fixed cells}

Prion uptake in BMDCs

Ten days post dissection; one million of BMDCs were plated overnight on Ibidi dishes (Biovalley) coated with fibronectin (SIGMA). Cells were then exposed to $2.5 \mathrm{mg}$ of $139 \mathrm{~A}$ scrapie brain homogenate for the indicated times, washed thoroughly in RPMI and fixed in 4\% paraformaldehyde. The cells were permeabilized with $0.1 \%$ Triton X-100 and treated with $3 \mathrm{M}$ guanidium thiocyanate to expose the PrPSc epitopes and labelled with anti PrP Sha31 antibody (SPIBIO) and with the cytosolic dye HSC CellMask blue (1:5,000) (Invitrogen). The cells were washed and mounted with Aqua-poly mount (Polysciences, Inc). Images were acquired with an Epi-fluorescence microscope (Zeiss axiovert 200M) controlled by Axiovision software. Random mosaics (3X3 fields) were obtained using a 63X objective Plan-APOCHROMAT objective (1.4 NA). All Z stacks were acquired with Z-steps of $0.4 \mu \mathrm{m}$. Representative tiles are presented. For higher magnification representations of the internalization process, a microscope confocal Andor Revolution Nipkow-Spinning Disk imaging system (Belfast, Ireland) was used. The Andor technology was installed on a Zeiss axiovert 200M microscope, equipped with an Andor EMCCD DV885 camera, three diode pumped solid state lasers with excitation at 405, 488 and $560 \mathrm{~nm}$, a piezo mono-objectif for fast 3D acquisitions, and a confocal head Spinning-disk Yokogawa CSU22. Images were acquired with an oil 63X Plan-APOCHROMAT objective (1.4 NA). All Zstacks were acquired at maximum speed of the microscope with Z-steps of $0.250 \mu \mathrm{m}$.

For wide-field analysis, cells were fixed with $4 \%$ paraformaldehyde for $10 \mathrm{~min}$. Phase contrast images were then acquired by high-resolution wide-field microscope Marianas (Intelligent Imaging Innovations) using a $63 \mathrm{X}$ oil objective. All Z stacks were acquired with Z-steps of 0.4 $\mu \mathrm{m}$.

\section{Proteinase K-digestion}

Prion detection in BMDCs.

Following incubation for the indicated times, cells were washed in PBS before lysis in TL1 buffer (50mM Tris $\mathrm{pH} 7.4,0.5 \%$ Sodium deoxycholate and $0.5 \%$ Triton X100). After a short centrifugation $(1,000 \mathrm{rpm}, 5 \mathrm{~min}), 50 \mu \mathrm{g}$ of cell lysates were treated with $2 \mu \mathrm{g}$ of PK for 30 minutes at $37^{\circ} \mathrm{C}$. Next, the proteins were methanol precipitated for 1 hour at $-20^{\circ} \mathrm{C}$ before centrifugation at $12,000 \mathrm{rpm}$ for $30 \mathrm{~min}$. Pellet were resuspended in sample buffer before analysis by SDS PAGE in 12\% acrylamide gels and Western Blot with Sha31 and secondary anti-mouse antibody coupled to horseradish peroxydase. Immunoreactivity was visualized by enhanced chemiluminescence (ECL, Amersham).

Prion detection in CGNs

The accumulation of PrPSc was analyzed in neuronal cultures at different times post infections. Neuron lysates performed in TL1 buffer were pre-cleared by centrifugation at 1,000 rpm for 5 min. $50 \mu \mathrm{g}$ of cell lysate proteins were treated with $0.5 \mu \mathrm{g}$ of $\mathrm{PK}$ for 30 minutes at $37^{\circ} \mathrm{C}$ before stopping the digestion with $5 \mathrm{mM}$ of PMSF. Proteins were methanol precipitated for 1 hour at $20^{\circ} \mathrm{C}$ before centrifugation at $12,000 \mathrm{rpm}$ for $30 \mathrm{~min}$. Pellet were resuspended in sample buffer and denatured before analysis by SDS-PAGE in 12\% acrylamide gels and Western Blot with Sha31 and secondary anti-mouse antibody coupled to horseradish peroxydase. Immunoreactivity was visualized by enhanced chemiluminescence (ECL, Amersham).

Prion detection in moRK13. 
The accumulation of PrPSc was analyzed in moRK13 after 18 hours of co-cultures. Lysates were performed in TL1 buffer after pre-clearing by centrifugation at 1,000 rpm for $5 \mathrm{~min}$. 20 or $200 \mu \mathrm{g}$ of cell lysate proteins were treated with $0.5 \mu \mathrm{g}$ or $5 \mu \mathrm{g}$ of $\mathrm{PK}$ for 1 hour at $37^{\circ} \mathrm{C}$ before methanol precipitation $\left(1\right.$ hour at $-20^{\circ} \mathrm{C}$ ). Proteins were then centrifuged at $12,000 \mathrm{rpm}$ for $30 \mathrm{~min}$. Pellet were resuspended in sample buffer and denatured before analysis by SDS-PAGE in 12\% acrylamide gels and Western Blot with Sha31 and secondary anti-mouse antibody coupled to horseradish peroxydase. Immunoreactivity was visualized by enhanced chemiluminescence (ECL, Amersham).

\section{RESULTS}

\section{Characterization of prion uptake in BMDCs}

We first analyzed the rate of internalization of PrPSc by BMDCs after in vitro exposure to infected brain homogenate. Ten days post plating, BMDCs were exposed to $139 \mathrm{~A}$ infected brain homogenate for $30 \mathrm{~min}, 1 \mathrm{hr}, 2 \mathrm{hrs}$ or $18 \mathrm{hrs}$, fixed, treated with guanidium and labelled with Sha31 antibody to detect PrPSc. Mosaics of different fields were obtained to analyze the overall spreading and endocytosis of PrPSc aggregates in BMDCs. Z-stacks were acquired to encompass all of the homogenate signals (see methods). In contrast to control BMDCs where no signal was observed after guanidium treatment (Supplementary Figure 1), large fields of view show that PrPSc aggregates are well spread and associated with the majority of the BMDCs exposed to the infected brain homogenate (Figure 1A). While most of the aggregates were outside the cells at the early time points (Figure 1A; $30 \mathrm{~min}-1 \mathrm{hr}$ ), overtime PrPSc aggregates were progressively internalized (Figure 1A; 2-18hrs). After $18 \mathrm{hrs}$, the PrPSc aggregates were found inside the cells, as evidenced by the perfect focus of both BMDCs and PrPSc aggregates (Figure 1A; 18hrs). Detailed confocal analyses and 3D reconstructions of the PrPSc aggregates associated with BMDCs confirmed their localisation at the cell surface and outside of the cells after $30 \mathrm{~min}$ or 1 hour of exposure (Figure 1B; 30-1hr, Movies S1-S4). After 2 hours, some PrPSc was still visualized at the level of the plasma membrane but could also be detected in the cytosol of most cells (Figure 1B; 2hrs, Movies S5-S6). Finally, after 18 hours of exposure, the localisation of PrPSc was drastically shifted and entirely restricted to the cytosol of the BMDCs (Figure 1B; 18hrs, Movies S7-S8). At this time point, no free PrPSc aggregates could be detected outside the BMDCs (Figure 1A-B).

These data demonstrate the rapid uptake of PrPSc homogenate by BMDCs after in vitro exposure. The kinetics of internalization observed are in accordance with the results previously described in rat BMDCs and langherans cells [39, 40]. Additionally, biochemical analyses of PrPSc internalization performed on BMDCs derived from KO or PrP over-expressing mice (tga20) showed a similar increase in PrPSc internalization up to 18 hours post exposure, indicating that prion uptake is independent of the levels of $\mathrm{PrPc}$ (Supplementary Figure 2).

\section{Characterization of PrPSe degradation in BMDCs}

Next, we wanted to investigate the fate of PrPSc once internalized by BMDCs. In vivo studies have identified DCs as important candidates during prion spreading from the periphery to the peripheral nervous system [24, 39]. However, subsequent in vitro experiments have indicated that the rapid uptake of PrPSc is progressively followed by prion degradation in various subsets of dendritic cells [39-42]. Because a rapid degradation of PrPSc would be inconsistent with a role of DCs in prion spreading, we investigated whether and how PrPSc was processed in BMDCs by analysing the levels of PrPres overtime following the uptake of prion homogenate (Figure 2A).

Ten days post plating, $10^{6}$ BMDCs were subjected to $2.5 \mathrm{mg}$ of brain homogenate (obtained from terminally infected mice injected with the 139A scrapie strain) for the duration of the experiment (Figure 2A). Alternatively, the cells were first allowed to internalize PrPSc for 18 hours, then washed and replated before performing PK assay (Supplementary Figure 3). Following prion 
capture, BMDCs isolated from wild type mice progressively degraded 139A prion aggregates as determined by the decrease of PrPres signal between 24 and 168 hours (C57B1/6) (Figure 2A and supplementary Figure 3). These results show a progressive clearance of prion aggregates by dendritic cells. However, it is also clear that following prion uptake, BMDCs are able to carry infectious PrPSc up to 4 days. This is consistent with a dual role of DCs both in the transfer of prions to other cells and in prion clearance overtime. This hypothesis is also supported by previous work indicating that in mice model, DCs with high content of cytoplasmic PrPSc aggregates could be detected in the lymph nodes from 8 to 16 hours post peripheral inoculation [39].

In order to understand whether PrPc had a role in PrPSc catabolism, we repeated the same experiments using BMDCs isolated either from KO mice or from tga20 mice, which express 10 times more PrPc than wild type mice (Figure 2 and Supplementary Figure 3; tga20 and KO). Western Blot quantifications of the PrPres signal indicated that 139A brain homogenate was catabolised overtime with similar kinetics by BMDCs isolated from $\mathrm{KO}$, wild type or tga20 mice (Figure 2B).

Overall, these data indicate that both PrPSc uptake and degradation are independent of PrPc expression.

\section{BMDCs transfer PrPSc to neuronal cells}

Having established that BMDCs retained PrPSc for at least 96 hours after its uptake (Figure 2A), we further investigated their ability to transfer PrPSc to primary cultures of neurons using in vitro co-cultures. To detect PrPSc transfer, BMDCs were loaded with 139A scrapie brain homogenate for 18 hours in order to allow complete PrPSc internalization (see Figure 1). Cells were then extensively washed before addition to the CGN primary cultures.

As previously described, co-cultures were established in a 4:1 ratio between neuronal and dendritic cells [37]. After overnight incubations, BMDCs were removed from the CGN cultures by extensive washes. The lysates of both removed BMDCs and neuronal cells were analysed for the presence of PrPres by Western Blot after PK treatment. Interestingly, under these conditions PrPres was detected only in the neurons and not in the BMDCs removed from the co-cultures indicating that a large amount of PrPSc had been transferred from the BMDCs to the neurons (Figure 3A, co-culture). We could exclude prion transfer from membrane associated PrPSc aggregates, since we demonstrated that at the time of the co-cultures with the primary neurons the PrPSc aggregates were localized exclusively inside the cytosol of BMDCs (see Figure 1A, B18hrs). Therefore, transfer could have occurred either through the secretion of PrPSc in the media or through direct passage from the cystosol of BMDCs to the cytosol of the neurons, possibly via TNTs as we had previously suggested [37].

To evaluate the possible role of the secretory pathway and more specifically of exosomal release [43-46] we examined whether prion transfer could occur through filters, which would allow the passage of secretory yesicles and exosomes. Quantitation of the PrPres signals demonstrated that the transfer efficiency is reduced by more than $98 \%$ when filters were used to separate the cultures, compared to direct co-cultures (Figure 3A). This suggested that PrPSc secretion was not involyed in the transfer (Figure 3A filter). However, to rule out the possibility that the filters could trap PrPSc aggregates, we analyzed whether prion transfer could be mediated by the supernatant of the scrapie-loaded BMDCs. To this aim, neurons were exposed to the supernatant of BMDCs loaded with 139A brain homogenate collected after 24 hours. After 18 hours of exposure to the conditioned medium, neurons were washed and analysed for PrPres. Similar to the filter conditions, neurons exposed to the supernatant of BMDCs did not contain high PrPres signals as compared to the signal obtained from the direct co-culture experiments (Figure 3B; supernatant), further suggesting that PrPSc secretion was not the main transfer mechanism.

Finally, to ensure that the PrPres signal observed in CGNs were not the results of BMDCs left in the cultures, we analyzed by Western Blot the presence of BMDCs in the CGN co-cultures 
using the BMDC cell-specific MHC class II antibody. BMDCs and non-exposed CGN cell extracts were used as positive and negative controls respectively (Figure 3C). As expected, a very strong signal for MHC Class II proteins was detected in BMDC cell extracts but not in nonexposed CGNs (NI) or in CGNs exposed to BMDCs through filter (filter) (Figure 3C). Interestingly, only a very faint signal was detected in CGNs directy exposed to BMDCs (coculture) (Figure 3C) indicating that the BMDCs were efficiently removed from the CGNs. This also excluded the possibility that the PrPres signals detected in CGNs post co-cultures could be derived from prion-loaded BMDCs.

Overall, these data demonstrate that efficient PrPSc transfer from BMDCs requires cell-tocell contact and does not appear to be associated with PrPSc secretion. In order to quantify the amount of PrP discharged by BMDCs, we analyzed the amount of PrPres remaining in BMDCs co-cultured directly or through filters with primary neurons (Figure 3A). Interestingly, different levels of PrPres could be detected in equivalent number of BMDCs from the different co-culture conditions (Figure 3A). Indeed, by normalizing the gel loading to $50 \mu \mathrm{g}$ of proteins of the different BMDCs lysates, we found that BMDCs seeded on filters contained much higher levels of PrPres compared to BMDCs seeded directly on top of CGNs (Figure 3A). Quantitation of PrPres signals indicated that direct co-cultures triggered $97 \%$ of PrPSc release as compared to filter conditions (Figure 3A). These data clearly indicate that the transfer of PrPSc from BMDCs to the primary neurons was triggered by direct cell-to-cell contact. Similar experiments were performed with epithelial moRK13 cells, which can be infected after prion transfer from BMDCs [37]. As in the case of primary neurons, moRK13 cells contained PrPres after 18 hours of direct co-culture with loaded BMDCs, but not if the cells were separated by filters or exposed to the supernatants of BMDCs (supplementary Figure 4). Interestingly, the amount of PrPres found in moRK13 was equivalent to $1 / 4$ of the total amount of PrPres found in loaded BMDCs and was comparable to the amount left in the BMDCs that were co-cultured through a filter. Therefore, these data highlight the important role of direct cell contact in the stimulation of prion discharge by BMDCs.

Furthermore, we observed that upon co-culture, BMDCs were able to interact with both the dendrites (Figure 3D; upper panel) and the cell bodies (Figure 3D; lower panel) of neuronal cells. These observations are in agreement with in vivo results [20,32], which show close contact between DCs and nerve fibres in lymph nodes of scrapie-infected animals.

\section{BMDCs efficiently transfer prion infectivity to neuronal cells}

Because we have previously shown that PrPSc transfer from BMDCs could result in de novo infection of primary neurons [37], we decided to further characterize the cellular mechanisms involved in the transfer of infectivity.

To this aim, after 12 hours of co-culturing with loaded-BMDCs, we analyzed the evolution of PrPres signals in primary neurons overtime, up to 3 weeks of culture. Direct co-cultures established between 139A-loaded BMDCs and CGNs from wild type C57BL/6 mice gave rise to neuronal infection as demonstrated by the progressive increase of PrPres signal observed from 7 to 21 days post co-culture (Figure 4A). On the other hand, similar experiments performed with CGNs derived from PrP KO mice did not show any PrPres signal even after 3 weeks of culture (Figure 4A). Since PrPSc transfer is similar in KO neurons compared to wild type neurons (data not shown), these data show that the PrPres signal observed in wild-type neurons derives from PrPSc neo-synthesis and is not the result of remnant PrPSc from BMDCs. Next, we analyzed whether there was transfer of infectivity from loaded-BMDCs to neurons in co-cultures separated through filters. As expected from the observed lack of transfer under these conditions (Figure 3A and supplementary Figure 4), we were unable to detect newly synthesized PrPSc in primary neurons maintained in culture up to three weeks after overnight filter co-culture with loaded BMDCs (Figure 4B). Finally, in order to analyze whether infection was due to an active transfer mechanism, we decided to alter our co-culture experiments in order to inhibit membrane remodelling. To this aim, loaded-BMDCs were fixed (with paraformaldehyde/gluteraldehyde 
solutions) before exposure to neuronal cultures. These treatments strongly inhibited the plasma membrane plasticity, blocking both TNT formation and PrPSc secretion. Similarly to the results obtained after co-culture through filters, fixation of BMDCs prior to the co-cultures did not result in neuronal infection as indicated by the absence of PrPres signals in the co-cultured neurons (Figure 4B). These data indicated that PrPSc infection results from an active process, which cannot occur upon fixation in a short 12 hours co-culture and requires cell-to-cell contact. Because, we excluded that in our experiments prion-transfer could occur via secretion, all our data are consistent with a role of TNT in intercellular spreading from BMDCs to neurons, as we have previously proposed [37] (see also Supplementary movie S9).

\section{DISCUSSION}

In this paper, we investigated the role of BMDCs in the processing and spreading of prions. To this aim, we developed an in vitro approach in which prion-loaded BMDCs were cocultured with cerebellar primary neurons. First, we characterized the prion uptake by BMDCs exposed to scrapie brain homogenate overtime by immunofluorescence analyses and 3D reconstructions (Figure 1 and supplementary Figure 2). While prion aggregates were mainly associated to the cell surface up to 2 hours post incubation, prion internalization was detected between 2 hours and 18 hours post-exposure resulting in a progressive shift of localisation of PrPSc from the plasma membrane to the cytosol.

Following scrapie uptake, we also demonstrated that BMDCs progressively degraded PrPSc between 24 and 72 hours post exposure. After 72 hours, we observed higher PrPSc catabolism leading to the rapid disappearance of PrPSc signal between 96 and 168 hours consistently with what was previously determined in other models [39, 40, 42, 47].

The fact that we have been able to detect consistent amounts of PrPres up to 72 hours post-loading indicates that after uptake BMDCs could present native prion proteins to other cell types during this time frame, before starting massive protein degradation. Furthermore, complementary experiments performed in BMDCs isolated from $\mathrm{KO}$ or PrP over-expressing mice indicated that neither the uptake as recently shown [38] nor the degradation of PrPSc was influenced by PrPc expression. Interestingly, similar experiments performed with different prion strains (22L and Me7) showed similar kinetics of uptake and catabolism of PrP (data not shown), suggesting that both mechanisms are not influenced by the different prion strains.

Next, we analyzed whether and how BMDCs transferred PrPSc to primary neurons. In these experiments, neurons were co-cultured with BMDCs two days post-plating, a stage of differentiation that we found facilitates the establishment of TNTs between neurons and BMDCs. We characterized our co-cultures by microscopic approaches and showed that after overnight cocultures BMDCs were either in close contact with dendrites or directly linked to neurons via TNTs (Supplementary movie S9). Recently, similar connections have been observed between BMDCs and peripheral neurons isolated from the dorsal root ganglia [38]. Having established the presence of such cell-to-cell contacts, we turned our attention to the characterization of intercellular prion transfer mechanisms. According to previous models of prion transfer, prionloaded BMDCs could transfer prions to neuronal cells by excreting PrPSc in the medium [48-51], by secretion of membrane exovesicles [43-46] or by direct cell-to-cell transfer [37, 52].

Direct co-cultures from BMDCs and neurons established for 18 hours allowed us to detect prion transfer to neuronal cells. However, when cells were co-cultured through filters, no detectable transfer was observed, arguing against the involvement of secreted PrPSc. To rule out the possibility that prion aggregates were retained on the filters, we also exposed neuronal cultures to medium conditioned by prion-loaded BMDCs. These experiments did not show significant prion transfer, as PrPres signal observed in neurons was much lower compared to the signal observed in the cases of direct cell-to-cell contact (Figure 3). We also determined the kinetics of prion transfer establishing short time co-cultures (from 30min to 4 hours), and demonstrated that efficient 
transfer required as little as 4 hours of co-culture, which is consistent with the time necessary for the establishment and transfer via TNTs in cell cultures (Supplementary Figure 5) [37, 53].

Overall, our results indicate that prion-loaded BMDCs are able to transfer PrPSc to neuronal cells upon direct and relatively short cell-to-cell contact. Although BMDCs could secrete prion-enriched exosomes, we have been unable to show the involvement of the secretory pathway in the PrPSc transfer to neuronal cells in our particular culturing conditions (e.g. short incubation time and $1 / 4$ cell dilution). Thus, although we cannot rule out other manners of transfer, our data indicate that the transfer mediated by direct cell-to-cell contact is very efficient.

Interestingly, no PrPres signal can be detected in BMDCs removed from direct contact with the neuronal cells, while PrPres was still present in BMDCs exposed to neurons through filters. These data strongly support the hypothesis that prion transfer from BMDCs to neurons is strongly induced upon cell-to-cell contact. Furthermore, because at the time of co-cultures (after 18 hours of uptake), all the PrPSc aggregates are in the cytosol of BMDCs (Figure 1) and not at the cell surface, these data suggest a transfer from the cytosol possibly via TNTs, excluding a transfer through plasma membrane to neighbouring cells. Interestingly, the transfer of PrPSc from Me7loaded BMDCs to DRG neurons has recently been examined [38]. In this paper, experimental conditions also suggested prion transfer through TNT like structures shown to connect BMDCs to DRG and excluded the involvement of PrPSc secretion.

Since we have previously shown that co-cultures with prion loaded BMDCs results in infection of primary neurons, next we followed up the cultures to determine the requirements for prion infection of the targeted neurons. Consistently with the transfer experiments, we found that prion infection is only detected after direct co-culture conditions and does not occur if cells are separated by filters or when co-cultures were performed with aldehyde fixed BMDCs. These experiments indicate that the transfer is an active mechanism requiring remodelling of the plasma membrane. Interestingly, a similar experiment performed by Kanu and co-workers had shown a reduction of $75 \%$ in the efficiency of transfer of infection from fixed scrapie SMB cells cocultured with targeted HMHB cells, as opposed to live cell co-cultures [52]. These data are in agreement with our conclusion that efficient transfer requires an active membrane remodelling, although it is clear that infection can be acquired via different mechanisms in less efficient manners (e.g. long co-cultures with fixed cells) [43-46, 52].

Here, using a number of restrictive experimental conditions such as short co-culture times, low BMDC/CGNs ratios, physical separation and pre-fixation of cells, we were able to show that direct cell-to-cell transfer of PrPSc between these two cell types occurs in a PrPc independent manner. Interestingly, having excluded transfer from the cell surface and by secretion, all our data point towards a role of TNT-like structures in the intercellular transfer of PrPSc from BMDCs to CGNs, similar to what was recently shown with DRG neurons [38]. Finally, our system of co-cultures suggests that dendritic cells could be important players during prion spreading in vivo and will allow further characterizations of prion spreading from the periphery to the nervous system of different scrapie strains, which could lead to a better understanding of the species barriers phenomenon.

\section{FIGURE LEGENDS}

\section{Figure 1. Time course of PrPSc internalization by BMDCs}

(A-B) BMDCs plated on fibronectin-coated Ibidi dishes were loaded with 139A brain homogenate for $30 \mathrm{~min}, 1 \mathrm{hr}, 2 \mathrm{hrs}$ or $18 \mathrm{hrs}$. The cells were then washed, fixed, denatured with guanidine-hydrochloride and immuno-labelled with anti-PrP antibody Sha31 and AlexaFluor-546 conjugated secondary antibody. HSC CellMask blue was used to label the cytosol of the BMDCs (blue). The brain homogenate revealed a punctuated PrPSc pattern (red). (A) Mosaics (3X3 fields) were acquired by wide-field microscopy. For the acquisitions, Z-stacks $(0.4 \mu \mathrm{m})$ were taken to visualize all of the PrPSc aggregates. In the early time points (30 min to $1 \mathrm{hr}$ ) PrPSc aggregates 
are found on top of the cells as determined by the different focal planes acquired. Overtime, the cells come into focus $(2 \mathrm{hrs})$ as the aggregates start to be internalized. After $18 \mathrm{hrs}$, all the aggregates appear to be inside the cells. (B) High-magnification acquisitions using an Andor spinning disk confocal microscope confirm the internalization of PrPSc aggregates overtime (2-18 hrs). Three-dimensional reconstructions were obtained for selected cells (insets) in both X-Y and $\mathrm{X}-\mathrm{Z}$ axis using OsiriX software. Scale bars represent $10 \mu \mathrm{m}$.

\section{Figure 2. Time course of PrPSc degradation in BMDCs.}

(A-B) BMDC cultures were established from C57BL/6 (left panel), tga20 (middle panel) or KO (right panel) mice. Ten days post plating, cells were exposed to 139A brain homogenate for the indicated times. (A) Cells were lysed and PK treated before analysis of PrPres expression by immunoblot using Sha31 antibody. Western Blot indicates a progressive decrease of the PrPres signal between 24 and 96 hours of exposure preceding total disappearance of the signal at 168 hours. (B) PrPSc degradation follows similar kinetics in BMDCs isolated from C57BL/6, tga20 or $\mathrm{KO}$ mice suggesting that the PrPSc catabolism we observed is independent of PrPc expression. The relative degradation of PrPSc in prion-loaded BMDCs was quantified from 2 independent experiments for $\mathrm{C} 57 \mathrm{BL} / 6$ and tga20 and from one experiment for $\mathrm{KO}$ cells.

\section{Figure 3. Characterization of PrPSc transfer from prion-loaded BMDCs to CGNs}

(A-B) Cell-to-cell contact is required for PrPSc transfer from BMDCs to neurons. BMDCs were exposed in vitro to $139 \mathrm{~A}$ brain homogenate for 18 hours. (A) Prion-loaded BMDCs were cocultured with neurons directly (co-culture) or through filters (filter). After 18 hours BMDCs were removed from the CGNs with extensive washes. The lysates of both the removed BMDCs and of the CGNs were PK treated to evaluate PrPSc transfer by immunoblot using Sha31 antibody. PrPres is only detected in neurons after direct co-culture suggesting that intercellular prion transfer cannot occur in the absence of cell-to-cell contact. On the other hand, prion protein is only visualized in BMDCs removed from filters, suggesting that direct contact triggers the prion discharge from BMDCs. PrPSc signal in CGNs and BMDCs was quantified from Western Blot from three different experiments and presented as relative percentages (lower panels). (B) To determine the impact of PrPSc present in the supernatant (e.g. exosomal release, vesicle secretion), prion-loaded BMDCs were co-cultured with neurons directly (co-culture), through filters (filter) or the neurons were exposed to the conditioned medium of loaded-BMDCs (supernatant). Similar to what was found in (A), PrPres was only detected in neurons after direct co-cultures. (C) To evaluate the efficiency of removal of BMDCs in CGN cultures, we evaluated the presence of MHC class II proteins in CGN lysates after co-cultures through filters (filter), direct exposure to BMDCs (co-cultures) or in non-exposed CGNs (NI). $50 \mu \mathrm{g}$ of proteins from BMDCs or CGNs were analyzed by Western blot with MHC class II and GADPH antibodies for normalization. While a strong MHC class II signal is detected in BMDC cell extracts, a faint signal is observed in CGNs only after direct exposure. (D) To assess the types of contact between the two cell populations in our co-cultures, prion-loaded BMDCs were co-cultured with CGNs two days post plating for 18 hours before fixation. Wide-field acquisitions were performed using a Marianas microscope (TripleI, germany) and selected frames of two different $Z$ stack acquisitions $(0.4 \mu \mathrm{m}$ steps) are shown. BMDCs (asterix) are in closed contacts with dendrites (arrow, upper panel) or neuronal cell body (arrow, lower panel). Scale Bar represents $10 \mu \mathrm{m}$.

\section{Figure 4. Characterization of the transfer of prion infectivity from BMDCs to CGNs}

(A) Kinetics of PrPSc accumulation in neuronal cells directly exposed to 139A-loaded BMDCs. C57BL/6 or KO CGNs were directly exposed to prion-loaded BMDCs (co-culture) or to $0.01 \%$ of 139A brain homogenate (homogenate) as a control. PrPres signal is detected in neuronal cell lysates by immunoblot using Sha31 antibody. PrPSc amplification is observed in C57 CGNs after exposure to 139A brain homogenate or prion-loaded BMDCs. No PrPres is detected in KO CGNs even after 21 days of culture. (B) Co-cultures were performed through filters or after fixation of 
BMDCs. Under these conditions, PrPSc amplification cannot be observed overtime. (C) Prionloaded BMDCs were co-cultured with CGNs two days post plating for 18 hours before fixation and microscopic observations. Wide-field acquisitions were performed using a Marianas microscope (TripleI, germany). Selected frames of $Z$ stack acquisitions ( $0.4 \mu \mathrm{m}$ steps) are shown. BMDCs (indicated with asterix) are connected to neurons via tunnelling nanotubes (arrows). Scale Bar represents $10 \mu \mathrm{m}$.

\section{ACKNOWLEDGEMENTS}

We thank A. Caputo and Z. Marijanovich for critical reading of the manuscript. We thank M. Baier for the 139A scrapie brain homogenate, A.F. Hill for the moRK13 cells and G. Milon for the M5/114 antibody. We are grateful for assistance with microscopy and image processing received from the Plate-forme Imagerie Dynamique at the Pasteur Institute.

\section{FUNDINGS}

This work is supported by grants to C.Z. from the European Union [FP6 Contract No 023183] (Strainbarrier), [FP7 Contract No 222887] (Priority) and from Agence Nationale de la Recherche, Contract No ANR-09-BLAN-0122 (Priontraf). KG is supported by the Pasteur Foundation Fellowship Program and MC is supported by a fellowship from the Ministère de Education Nationale et de la Recherche.

\section{REFERENCES}

1 Andreoletti, O., Berthon, P., Marc, D., Sarradin, P., Grosclaude, J., van Keulen, L., Schelcher, F., Elsen, J. M. and Lantier, F. (2000) Early accumulation of $\operatorname{PrP}(\mathrm{Sc})$ in gut-associated lymphoid and nervous tissues of susceptible sheep from a Romanov flock with natural scrapie. $\mathrm{J}$ Gen Virol. 81, 3115-3126

2 Heggebo, R., Press, C. M., Gunnes, G., Gonzalez, L. and Jeffrey, M. (2002) Distribution and accumulation of PrP in gut-associated and peripheral lymphoid tissue of scrapie-affected Suffolk sheep. J Gen Virol. 83, 479-489

3 Aguzzi, A. (2003) Prions and the immune system: a journey through gut, spleen, and nerves. Adv Immunol. 81, 123-171

4 Aguzzi, A. and Polymenidou, M. (2004) Mammalian prion biology: one century of evolving concepts. Cell. 116, 313-327

5 Mabbott, N. A. and MacPherson, G. G. (2006) Prions and their lethal journey to the brain. Nat Rev Microbiol. 4, 201-211

6 Mallucci, G. R. (2009) Prion neurodegeneration: starts and stops at the synapse. Prion. 3, 195-201

7 McBride, P. A., Eikelenboom, P., Kraal, G., Fraser, H. and Bruce, M. E. (1992) PrP protein is associated with follicular dendritic cells of spleens and lymph nodes in uninfected and scrapie-infected mice. J Pathol. 168, 413-418

8 van Keulen, L. J., Schreuder, B. E., Meloen, R. H., Mooij-Harkes, G., Vromans, M. E. and Langeveld, J. P. (1996) Immunohistochemical detection of prion protein in lymphoid tissues of sheep with natural scrapie. J Clin Microbiol. 34, 1228-1231

9 Brown, K. L., Stewart, K., Ritchie, D. L., Mabbott, N. A., Williams, A., Fraser, H., Morrison, W. I. and Bruce, M. E. (1999) Scrapie replication in lymphoid tissues depends on prion protein-expressing follicular dendritic cells. Nat Med. 5, 1308-1312 
10 Hill, A. F., Butterworth, R. J., Joiner, S., Jackson, G., Rossor, M. N., Thomas, D. J., Frosh, A., Tolley, N., Bell, J. E., Spencer, M., King, A., Al-Sarraj, S., Ironside, J. W., Lantos, P. L. and Collinge, J. (1999) Investigation of variant Creutzfeldt-Jakob disease and other human prion diseases with tonsil biopsy samples. Lancet. 353, 183-189

11 Jeffrey, M., McGovern, G., Martin, S., Goodsir, C. M. and Brown, K. L. (2000) Cellular and sub-cellular localisation of PrP in the lymphoreticular system of mice and sheep. Arch Virol Suppl, 23-38

12 Mabbott, N. A. and Bruce, M. E. (2002) Follicular dendritic cells as targets for intervention in transmissible spongiform encephalopathies. Semin Immunol. 14, 285-293

13 Mabbott, N. A., Mackay, F., Minns, F. and Bruce, M. E. (2000) Temporary inactivation of follicular dendritic cells delays neuroinvasion of scrapie. Nat Med. 6, 719-720

14 Montrasio, F., Frigg, R., Glatzel, M., Klein, M. A., Mackay, F., Aguzzi, A. and Weissmann, C. (2000) Impaired prion replication in spleens of mice lacking functional follicular dendritic cells. Science. 288, 1257-1259

15 Mabbott, N. A., Young, J., McConnell, I. and Bruce, M. E. (2003) Follicular dendritic cell dedifferentiation by treatment with an inhibitor of the lymphotoxin pathway dramatically reduces scrapie susceptibility. J Virol. 77, 6845-6854

16 Kimberlin, R. H. and Walker, C. A. (1989) Pathogenesis of scrapie in mice after intragastric infection. Virus Res. 12, 213-220

17 Beekes, M., McBride, P. A. and Baldauf, E. (1998) Cerebral targeting indicates vagal spread of infection in hamsters fed with scrapie. J Gen Virol. 79 (Pt 3), 601-607

18 Beekes, M. and McBride, P. A. (2000) Early accumulation of pathological PrP in the enteric nervous system and gut-associated lymphoid tissue of hamsters orally infected with scrapie. Neurosci Lett. 278, 181-184

19 Defaweux, V., Dorban, G., Antoine, N., Piret, J., Gabriel, A., Jacqmot, O., Falisse-Poirier, N., Flandroy, S., Zorzi, D. and Heinen, E. (2007) Neuroimmune connections in jejunal and ileal Peyer's patches at various bovine ages: potential sites for prion neuroinvasion. Cell Tissue Res. 329, 35-44

20 Dorban, G., Defaweux, V., Levavasseur, E., Demonceau, C., Thellin, O., Flandroy, S., Piret, J., Falisse, N., Heinen, E. and Antoine, N. (2007) Oral scrapie infection modifies the homeostasis of Peyer's patches' dendritic cells. Histochem Cell Biol. 128, 243-251

21 von Poser-Klein, C., Flechsig, E., Hoffmann, T., Schwarz, P., Harms, H., Bujdoso, R., Aguzzi, A. and Klein, M. A. (2008) Alteration of B-cell subsets enhances neuroinvasion in mouse scrapie infection. J Virol. 82, 3791-3795

22 McGovern, G., Mabbott, N. and Jeffrey, M. (2009) Scrapie affects the maturation cycle and immune complex trapping by follicular dendritic cells in mice. PLoS ONE. 4, e8186

23 Prinz, M., Heikenwalder, M., Junt, T., Schwarz, P., Glatzel, M., Heppner, F. L., Fu, Y. X., Lipp, M. and Aguzzi, A. (2003) Positioning of follicular dendritic cells within the spleen controls prion neuroinvasion. Nature 425, 957-962

24 Aucouturier, P., Geissmann, F., Damotte, D., Saborio, G. P., Meeker, H. C., Kascsak, R., Carp, R. I. and Wisniewski, T. (2001) Infected splenic dendritic cells are sufficient for prion transmission to the CNS in mouse scrapie. J Clin Invest. 108, 703-708

25 Huang, F. P. and MacPherson, G. G. (2004) Dendritic cells and oral transmission of prion diseases. Adv Drug Deliv Rev. 56, 901-913

26 Raymond, C. R. and Mabbott, N. A. (2007) Assessing the involvement of migratory dendritic cells in the transfer of the scrapie agent from the immune to peripheral nervous systems. J Neuroimmunol. 187, 114-125

27 Cordier-Dirikoc, S. and Chabry, J. (2008) Temporary depletion of CD11c+ dendritic cells delays lymphoinvasion after intraperitonal scrapie infection. J Virol. 82, 8933-8936

28 Rescigno, M., Rotta, G., Valzasina, B. and Ricciardi-Castagnoli, P. (2001) Dendritic cells shuttle microbes across gut epithelial monolayers. Immunobiology. 204, 572-581 
29 Heppner, F. L., Christ, A. D., Klein, M. A., Prinz, M., Fried, M., Kraehenbuhl, J. P. and Aguzzi, A. (2001) Transepithelial prion transport by M cells. Nat Med. 7, 976-977

30 Mishra, R. S., Basu, S., Gu, Y., Luo, X., Zou, W. Q., Mishra, R., Li, R., Chen, S. G., Gambetti, P., Fujioka, H. and Singh, N. (2004) Protease-resistant human prion protein and ferritin are cotransported across Caco-2 epithelial cells: implications for species barrier in prion uptake from the intestine. J Neurosci. 24, 11280-11290

31 Banchereau, J., Briere, F., Caux, C., Davoust, J., Lebecque, S., Liu, Y. J., Pulendran, B. and Palucka, K. (2000) Immunobiology of dendritic cells. Annu Rev Immunol. 18, 767-811 32 Defaweux, V., Dorban, G., Demonceau, C., Piret, J., Jolois, O., Thellin, O., Thielen, C., Heinen, E. and Antoine, N. (2005) Interfaces between dendritic cells, other immune cells, and nerve fibres in mouse Peyer's patches: potential sites for neuroinvasion in prion diseases. Microsc Res Tech. 66, 1-9

33 Dorban, G., Defaweux, V., Demonceau, C., Flandroy, S., Van Lerberghe, P. B., FalissePoirrier, N., Piret, J., Heinen, E. and Antoine, N. (2007) Interaction between dendritic cells and nerve fibres in lymphoid organs after oral scrapie exposure. Virchows Arch. 451, 1057-1065

34 Raymond, C. R., Aucouturier, P. and Mabbott, N. A. (2007) In vivo depletion of CD11c+ cells impairs scrapie agent neuroinvasion from the intestine. J Immunol. 179, 7758-7766

35 Marruchella, G., Ligios, C., Albanese, V., Cancedda, M. G., Madau, L., LalattaCosterbosa, G., Mazzoni, M., Clavenzani, P., Chiocchetti, R., Sarli, G., De Grossi, L., Agrimi, U., Aguzzi, A. and Di Guardo, G. (2007) Enteroglial and neuronal involvement without apparent neuron loss in ileal enteric nervous system plexuses from scrapie-affected sheep. J Gen Virol. 88, 2899-2904

36 Chiocchetti, R., Mazzuoli, G., Albanese, V., Mazzoni, M., Clavenzani, P., LalattaCosterbosa, G., Lucchi, M. L., Di Guardo, G., Marruchella, G. and Furness, J. B. (2008) Anatomical evidence for ileal Peyer's patches innervation by enteric nervous system: a potential route for prion neuroinvasion? Cell Tissue Res. 332, 185-194

37 Gousset, K., Schiff, E., Langevin, C., Marijanovic, Z., Caputo, A., Browman, D. T., Chenouard, N., de Chaumont, F., Martino, A., Enninga, J., Olivo-Marin, J. C., Mannel, D. and Zurzolo, C. (2009) Prions hijack tunnelling nanotubes for intercellular spread. Nat Cell Biol. 11, 328-336

38 Dorban, G., Defaweux, V., Heinen, E. and Antoine, N. (2010) Spreading of prions from the immune to the peripheral nervous system; a potential implication of dendritic cells. Histochem Cell Biol

39 Huang, F. P., Farquhar, C. F., Mabbott, N. A., Bruce, M. E. and MacPherson, G. G. (2002) Migrating intestinal dendritic cells transport $\operatorname{PrP}(\mathrm{Sc})$ from the gut. J Gen Virol. 83, 267271

40 Mohan, J., Hopkins, J. and Mabbott, N. A. (2005) Skin-derived dendritic cells acquire and degrade the scrapie agent following in vitro exposure. Immunology. 116, 122-133

41 Luhr, K. M., Wallin, R. P., Ljunggren, H. G., Low, P., Taraboulos, A. and Kristensson, K. (2002) Processing and degradation of exogenous prion protein by CD11c $(+)$ myeloid dendritic cells in vitro. J Virol. 76, 12259-12264

42 Rybner-Barnier, C., Jacquemot, C., Cuche, C., Dore, G., Majlessi, L., Gabellec, M. M., Moris, A., Schwartz, O., Di Santo, J., Cumano, A., Leclerc, C. and Lazarini, F. (2006) Processing of the bovine spongiform encephalopathy-specific prion protein by dendritic cells. J Virol. 80, $4656-4663$

43 Fevrier, B., Vilette, D., Archer, F., Loew, D., Faigle, W., Vidal, M., Laude, H. and Raposo, G. (2004) Cells release prions in association with exosomes. Proc Natl Acad Sci U S A. 101, 9683-9688

44 Leblanc, P., Alais, S., Porto-Carreiro, I., Lehmann, S., Grassi, J., Raposo, G. and Darlix, J. L. (2006) Retrovirus infection strongly enhances scrapie infectivity release in cell culture. EMBO J. 25, 2674-2685 
45 Vella, L. J., Sharples, R. A., Lawson, V. A., Masters, C. L., Cappai, R. and Hill, A. F. (2007) Packaging of prions into exosomes is associated with a novel pathway of PrP processing. J Pathol. 211, 582-590

46 Alais, S., Simoes, S., Baas, D., Lehmann, S., Raposo, G., Darlix, J. L. and Leblanc, P. (2008) Mouse neuroblastoma cells release prion infectivity associated with exosomal vesicles. Biol Cell. 100, 603-615

47 Luhr, K. M., Nordstrom, E. K., Low, P., Ljunggren, H. G., Taraboulos, A. and Kristensson, K. (2004) Scrapie protein degradation by cysteine proteases in CD11c+ dendritic cells and GT1-1 neuronal cells. J Virol. 78, 4776-4782

48 Schatzl, H. M., Laszlo, L., Holtzman, D. M., Tatzelt, J., DeArmond, S. J., Weiner, R. I., Mobley, W. C. and Prusiner, S. B. (1997) A hypothalamic neuronal cell line persistently infected with scrapie prions exhibits apoptosis. J Virol. 71, 8821-8831

49 Archer, F., Bachelin, C., Andreoletti, O., Besnard, N., Perrot, G., Langevin, C., Le Dur, A., Vilette, D., Baron-Van Evercooren, A., Vilotte, J. L. and Laude, H. (2004) Cultured peripheral neuroglial cells are highly permissive to sheep prion infection. J Virol. 78, 482-490

50 Cronier, S., Laude, H. and Peyrin, J. M. (2004) Prions can infect primary cultured neurons and astrocytes and promote neuronal cell death. Proc Natl Acad Sci U S A. 101, 12271-12276

51 Baron, G. S., Magalhaes, A. C., Prado, M. A. and Caughey, B. (2006) Mouse-adapted scrapie infection of SN56 cells: greater efficiency with microsome-associated versus purified PrPres. J Virol. 80, 2106-2117

52 Kanu, N., Imokawa, Y., Drechsel, D. N., Williamson, R. A., Birkett, C. R., Bostock, C. J. and Brockes, J. P. (2002) Transfer of scrapie prion infectivity by cell contact in culture. Curr Biol. 12, 523-530

53 Bukoreshtliev, N. V., Wang, X., Hodneland, E., Gurke, S., Barroso, J. F. and Gerdes, H. H. (2009) Selective block of tunneling nanotube (TNT) formation inhibits intercellular organelle transfer between PC12 cells. FEBS Lett. 583, 1481-1488

54 Bueler, H., Fischer, M., Lang, Y., Bluethmann, H., Lipp, H. P., DeArmond, S. J., Prusiner, S. B., Aguet, M. and Weissmann, C. (1992) Normal development and behaviour of mice lacking the neuronal cell-surface PrP protein. Nature. 356, 577-582

55 Fischer, M., Rulicke, T., Raeber, A., Sailer, A., Moser, M., Oesch, B., Brandner, S., Aguzzi, A. and Weissmann, C. (1996) Prion protein (PrP) with amino-proximal deletions restoring susceptibility of PrP knockout mice to scrapie. EMBO J. 15, 1255-1264

56 Mederle, I., Le Grand, R., Vaslin, B., Badell, E., Vingert, B., Dormont, D., Gicquel, B. and Winter, N. (2003) Mucosal administration of three recombinant Mycobacterium bovis BCGSIVmac251 strains to cynomolgus macaques induces rectal IgAs and boosts systemic cellular immune responses that are primed by intradermal vaccination. Vaccine. 21, 4153-4166 

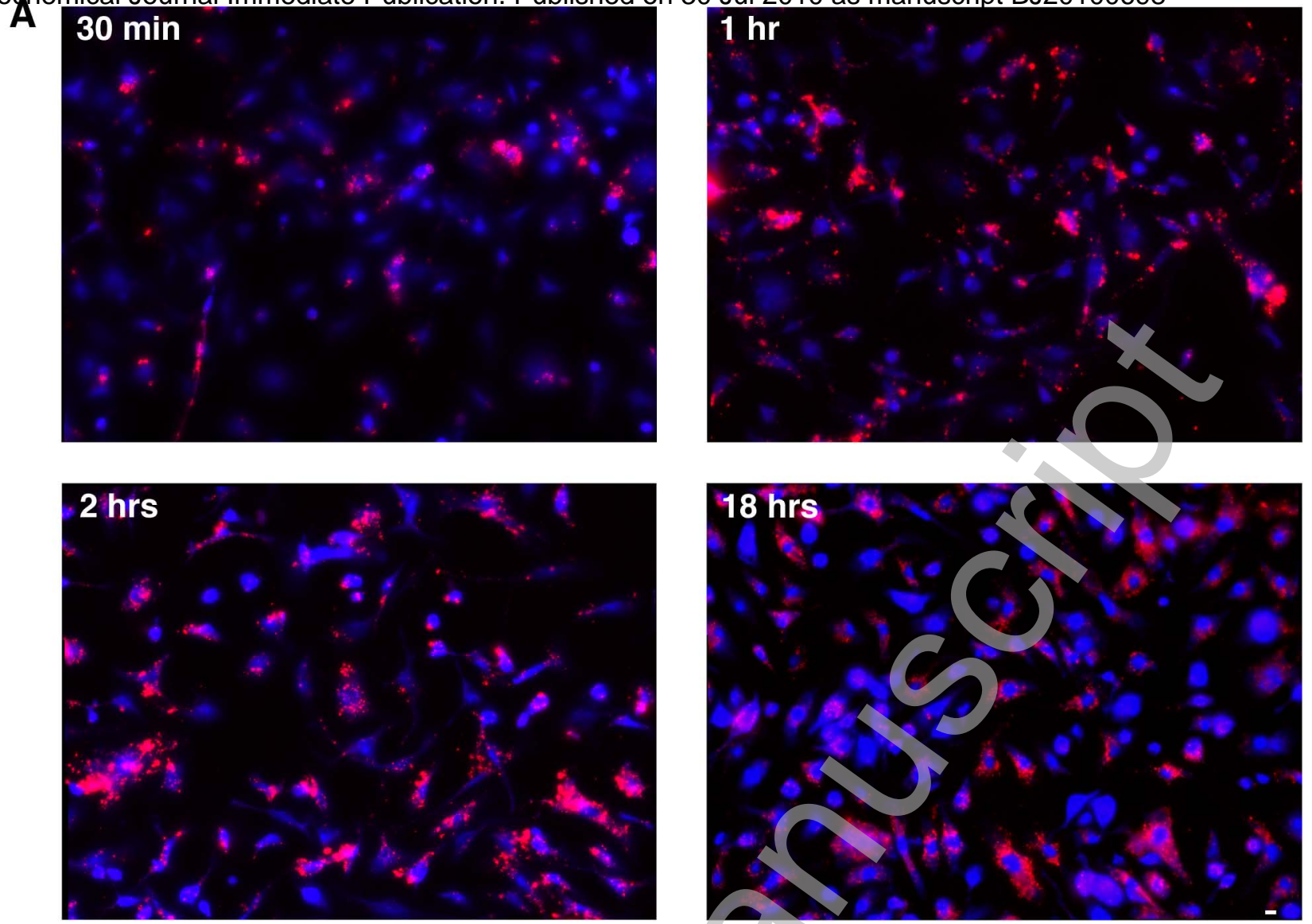

B
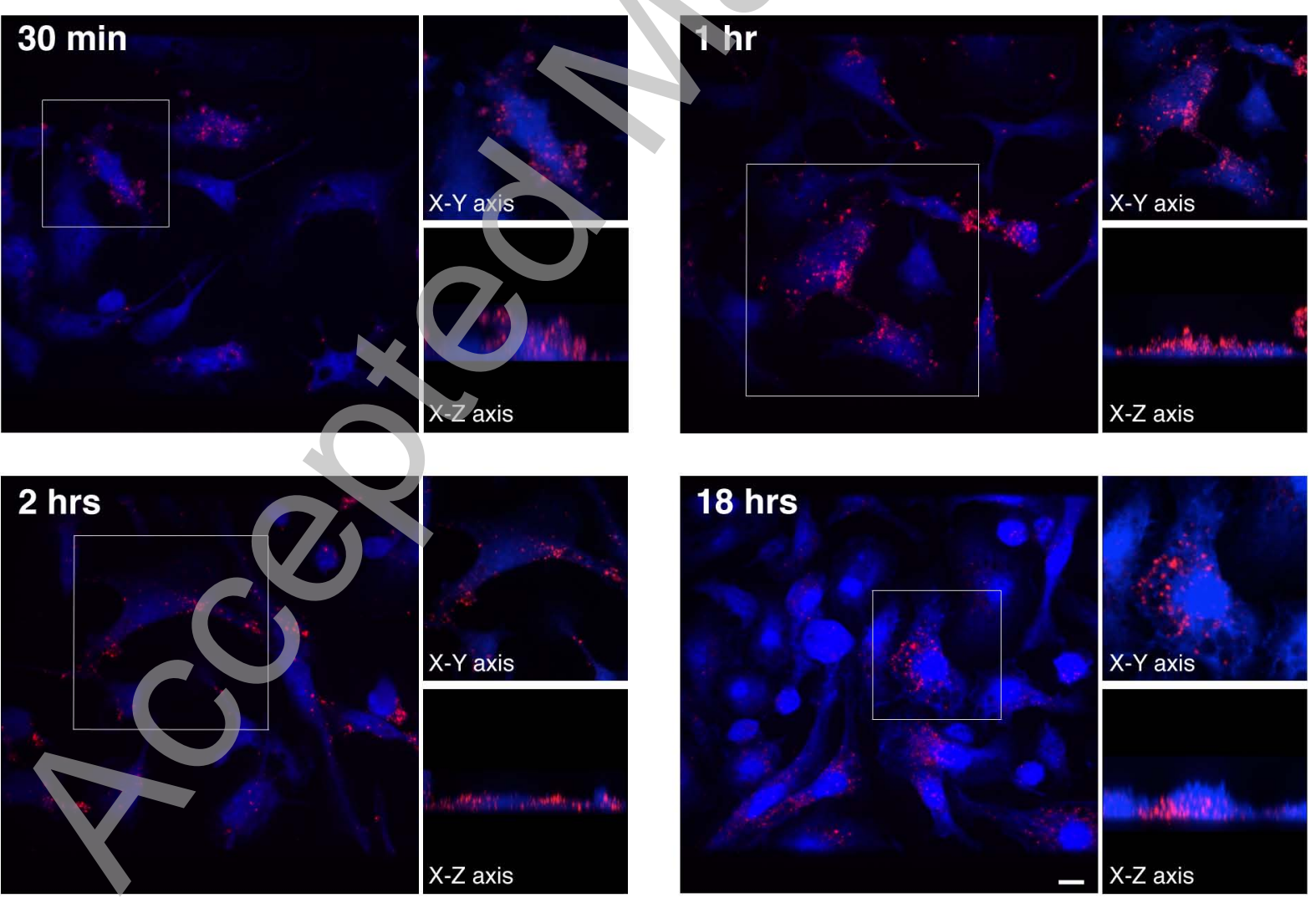

\section{Figure 1}


A
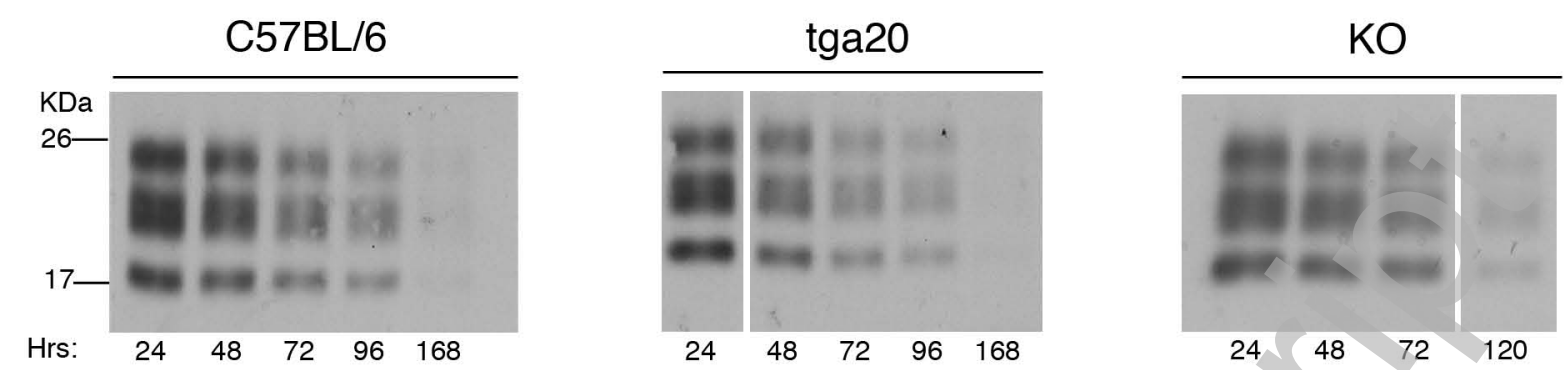

B
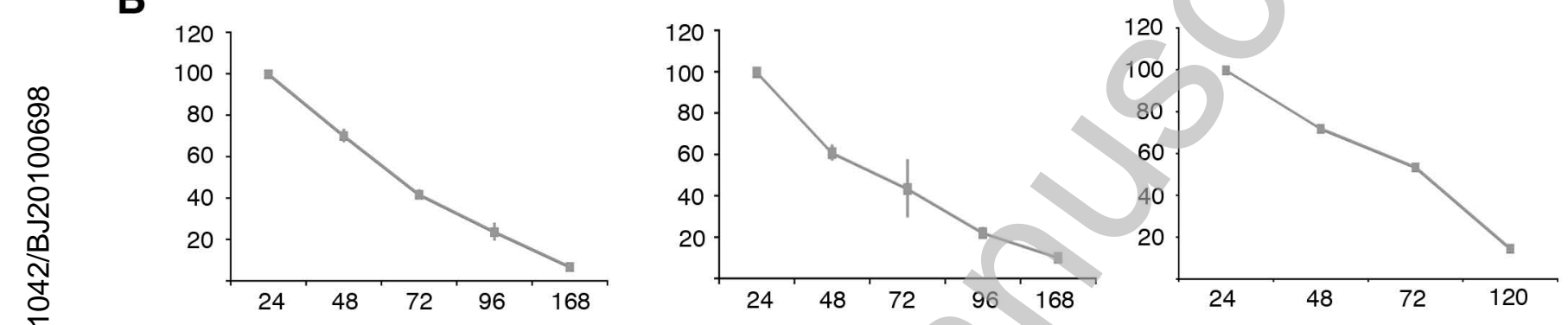

\section{Figure 2}


BA Aiochemical Journal Immediate Publication. Published on 30 Jul 2010 as manuscript BJ20100698
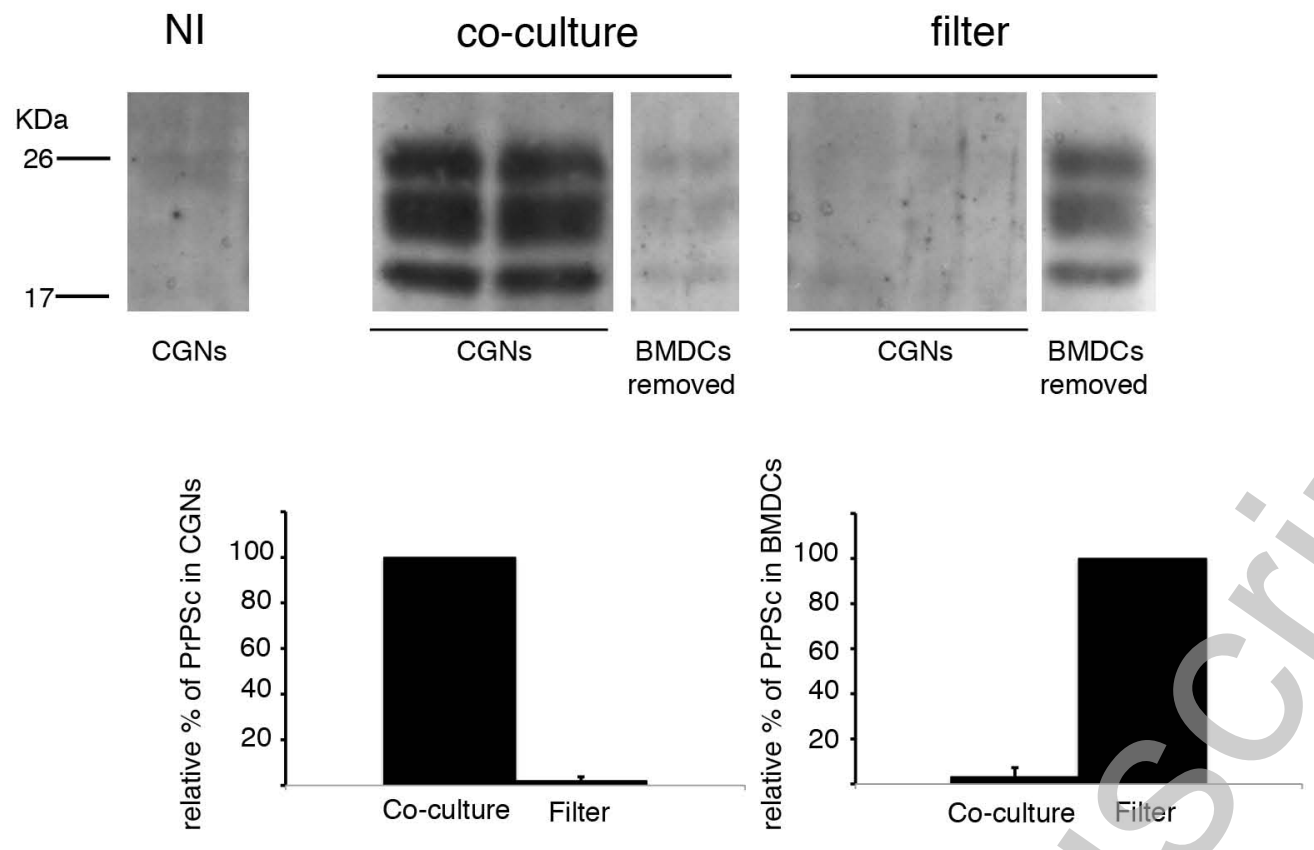

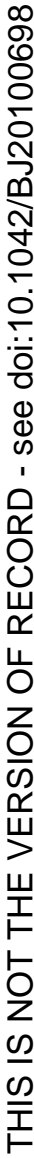

B
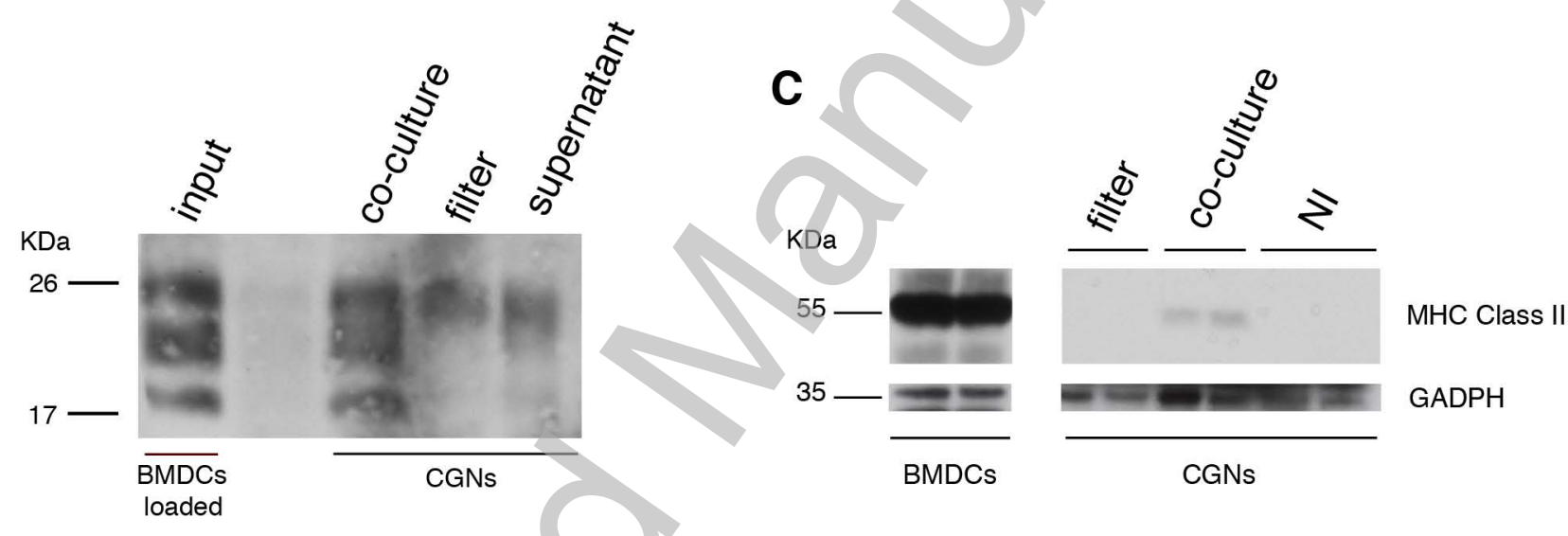

D
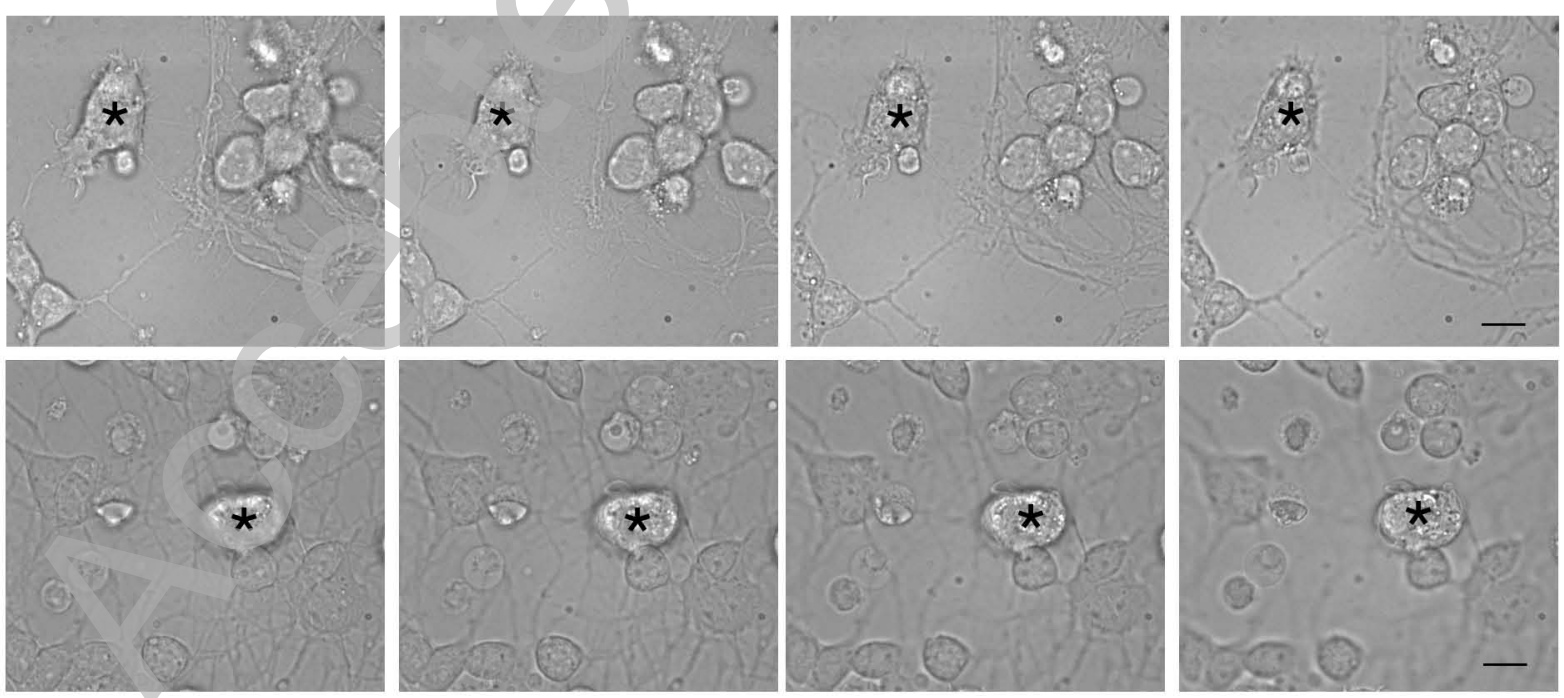

\section{Figure 3}


A

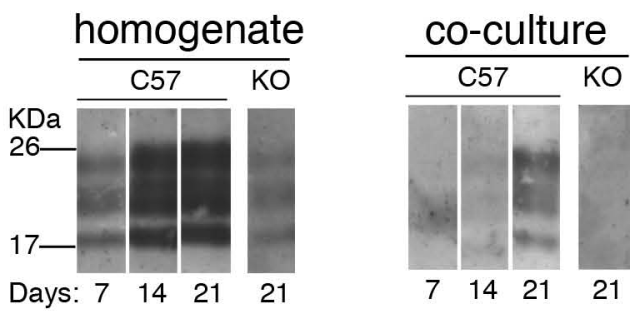

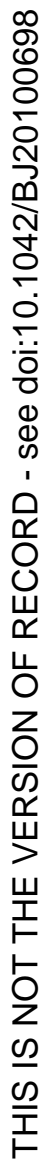

B homogenate

BMDCs
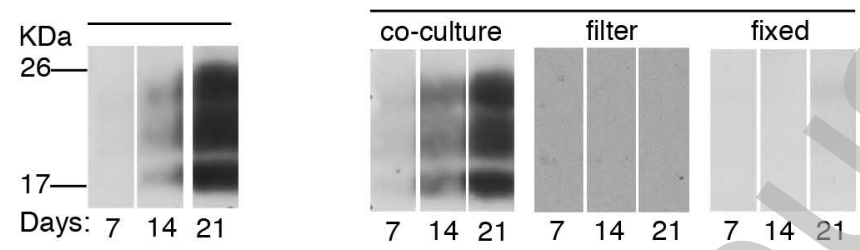

C
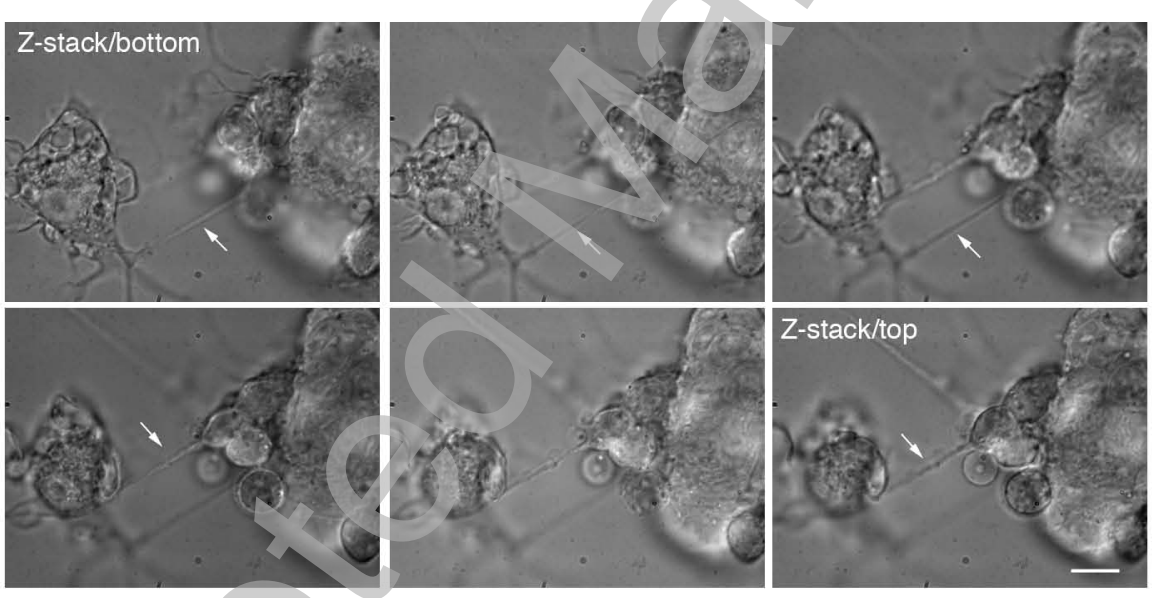

Figure 4 